\title{
Emergency Surgery Versus Colorectal Stenting for the Management of Left-sided Malignant Colon Obstructions: A Prospective Cohort Study
}

\section{${\text { Giorgi Merabishvili }{ }^{1,2} \text {, Ia Agdgomelashvili }{ }^{3,4} \text {, Baadur Mosidze }}^{5,6}$ and Zaza Demetrashvili ${ }^{7,8}$}

${ }^{1}$ Doctorate, Department of Surgery, Tbilisi State Medical University, Tbilisi, Georgia ${ }^{2}$ General surgeon of Kipshidze Central University Hospital, Tbilisi, Georgia

${ }^{3}$ Doctorate, Department of Surgery, Tbilisi State Medical University, Tbilisi, Georgia ${ }^{4}$ Head of Department of Anesthesiology of High Technology Medical Center, University Clinic, Tbilisi, Georgia

${ }^{5}$ Professor, Head of Department of Surgery, Tbilisi State Medical University, Tbilisi, Georgia

${ }^{6}$ Head of Department of Surgery of High Technology Medical Center, University, Tbilisi, Georgia

${ }^{7}$ Associate Professor, Department of Surgery, Tbilisi State Medical University, Tbilisi, Georgia

${ }^{8}$ Senior General Surgeon of Kipshidze Central University Hospital, Tbilisi, Georgia

*Corresponding Author: Zaza Demetrashvili MD, FACS, Associate Professor, Department of Surgery, Tbilisi State Medical University.

E-mail: zdemetr@yahoo.com
Received: January 30, 2021

Published: March 05, 2021

(C) All rights are reserved by Zaza

Demetrashvili.

\section{Abstract}

Background: The aim of our prospective study is to compare and analyze the results of two treatment methods of left-sided malignant colon obstructions: emergency surgery and colonic stenting.

Materials and Methods: 30 Patients with diagnosis of resectable left-sided malignant colon obstructions were enrolled in this study. The patients were assigned into two groups: the endoscopic colon stenting followed by elective surgery group and the emergency surgery group. Several clinical characteristics were determined and compared between the groups. Among patients who underwent emergency colon stenting, length of procedure, the number of successful stenting procedures, hospital stay days, period of time before elected surgery, post procedure complications and mortality were analyzed. In the emergency surgery group, type of surgeries, duration of the surgery, hospital stay days, postoperative complications (during 30 days after surgery) and mortality was assessed.

Results: 14 patients were enrolled in the stenting group and 16 patients were enrolled in the emergency surgery group. In 10 out of 14 patients (71.4\%) (successful stenting procedure) had undergone different types of colon resections with primary anastomosis. In case of 4 patients (28.6\%) it was not successful and emergency surgery (Hartmann's procedure) was done. In emergency surgery group 12 patients (75\%) had undergone Hartmann's procedure; rest 4 patients (25\%) had undergone different types of colon resections with primary anastomosis. There was no mortality in stenting group, but there was 1 mortality in emergency surgery group. In stenting group, there were 4 complications (28.6\%) (1 intra abdominal abscess after colorectal anastomosis, which was cured with antibiotic therapy and percutaneous drainage; 3 cases of wound infections) and in emergency surgery group there were 8 (50\%) complications (6 - wound infections, 1-necrosis of colostomy 1- leak of colorectal anastomosis). But this difference is not statistically reliable. In stenting group hospital stay were - 6 days and in emergency surgery group, it was 8 days. This difference is statistically reliable $(\mathrm{P}=0.02)$.

Conclusion: For the management of left-sided malignant colon obstructions, colon stenting followed with elective surgery, should be preferred rather than emergency surgery. In future it's needed to perform the randomized trials, which will study the long-term outcomes (recurrence of cancer, survival rate) of this treatment method.

Keywords: Colorectal Cancer; Self-expanding Metallic Stent; Colon Stenting; Large Bowel Malignant Obstruction 


\section{Introduction}

Acute colorectal obstructions may be observed in about $25 \%$ of patients with colorectal cancer and it often leads to emergency surgical decompression [1,2]. Since its introduction in the early 1990s, the self-expandable metal stent (SEMS) has been increasingly used for the management of malignant colorectal obstructions, not only as a palliative method, but also as a preoperative treatment in surgical candidates.

The first being used by Dohmoto., et al. in 1991 and Tejero., et al. described the use of colon stents as a "bridge to surgery" in $1994[3,4]$. This has been the subject of many reviews which highlight its efficacy, particularly in reducing colostomy rates, allowing quicker return to oral diet, minimizing extended post-operative stay and some quality of life (QoL) benefits [5]. Xinopoulos., et al. demonstrated that self-expanding metallic stent (SEMS) placement represents an alternative approach to colostomy for patients with inoperable malignant colon strictures [6]. For palliative purposes, where surgical management might be considered unethical, stenting is likely to be a useful option, as it avoids a colostomy and improves the quality of life in many patients. The uncertainty in managing patients with malignant colon obstructions has led to a more cautious use of stenting technology as community equipoise exists [7].

The main goal of our study is to compare and analyze the results of surgical treatment of left sided colon cancer to the results of stenting method of obstructed colon.

\section{Material and Methods}

From October 2017 to January 2020 patients over 18 years of age who treated to our hospital with diagnosis of resectable leftsided malignant colon obstructions were enrolled in this prospective study. The inclusion criteria were: symptoms of left-sided malignant colon obstruction confirmed by computed tomography (CT) of abdomen and pelvis, or colonoscopy, and patient's consent to participate in the study. The exclusion criteria were: peritonitis, bowel perforation, or sepsis demanding urgent surgery, distal rectal cancers $<8 \mathrm{~cm}$ from the anal verge, patients with the American Society of Anesthesiologists (ASA) scores 4 and 5, obstructions due to non-colon malignancies, or from benign origin and patients' refusal to participate in the study. Eligible patients were assigned to one of two groups: those who have undergone emergency endoscopic colon stenting, followed by elective surgery at a later date (Group A) and those who have undergone emergency surgery (Group B). The assignment of the patients to the specific groups was performed by the clinical manager, who was not involved in the surgical procedures. Patients, who had successful stenting were discharged and readmitted for elective surgery in about 7 to 14 days after stenting. Patients with unsuccessful stenting underwent emergency surgery. All of these operations were performed with open surgery method by 3 surgeons, who were well experienced in colorectal surgeries.

For diagnostic method were used: Colonoscopy, CT of abdomen and pelvis and in some cases MRT. Stenting Procedure was done with Olympus CV 160 and self-expandable WallFlex stent 30/90mm (Boston Scientific, USA) without balloon-dilation. Clinical success was defined as the colon decompression within $72 \mathrm{~h}$ after successful placement of the stent, with passage of stools and confirmed on plan abdominal radiograph.

The clinical characteristics were collected for each patient: gender, age, American society of Anesthesiologists (ASA) risk group, comorbidities, location of tumor, stage of tumor, and associated chronic diseases. In Group A, we investigated the following results: length of procedure, the number of successful stenting procedures, hospital stay days, period of time before elected surgery, post procedure complications (pain, stent migration, stent obstruction, bowel perforation), mortality. In Group B we investigated and compared following outcomes: type of surgeries, duration of the surgery, hospital stay days, postoperative complications (during 30 days after surgery) and mortality.

The study was reviewed and approved by the Institutional review boards of the Tbilisi State Medical University (Tbilisi, Georgia) ethics committee. The study was registered on ClinicalTrials. gov:NCT04449822.

\section{Statistical methods}

Sample size calculation was performed for t-test to compare means of continuous variables for the following parameters: E/ $\mathrm{S}=0.5$, Power $=80 \%$, alpha $=0.05$.

Descriptive statistics methods were used to characterize each variable. Comparison of continuous variables was performed by independent samples t-test or the Mann-Whitney U test according to the normality of the variables. Categorical variables were evaluated by two-tailed Chi-square test or Fisher's exact test where appropriate (for expected frequencies $<5$ ). The threshold for statistical significance was set to $\mathrm{P}<0.05$. The statistical tests were performed by IBM SPSS statistics package v23.0 (IBM Corporation, Armonk, New York).

\section{Results}

30 patients admitted with left-sided malignant colon obstructions were recruited. 14 patients were randomized to the stenting 
group and 16 patients were randomized in the emergency surgery group. There were no significant differences in the clinical characteristics between these two groups (Table 1). In 10 patients (71.4\%) out of 14 stenting procedure was successful. In case of 4 patients $(28.6 \%)$ it was not successful and emergency surgery was done. Length of stenting procedure was variable between 25 $90 \mathrm{~min}$ (mid. time $-45.6 \pm 16.9 \mathrm{~min}$ ). After successfully performed stenting procedure, patients were discharged in 3-9 days (mid 3.6 \pm 0.7 day). After successful stenting procedure, elective surgery was done during 7-24 days period (mid $12.4 \pm 4.9$ day).

\begin{tabular}{|c|c|c|c|}
\hline Characteristics & $\begin{array}{l}\text { Stenting group } \\
\qquad(n=14)\end{array}$ & $\begin{array}{c}\text { Emergency } \\
\text { surgery } \\
\text { group } \\
(n=16)\end{array}$ & P value \\
\hline Male:Female & $9: 5$ & $9: 7$ & 0.72 \\
\hline Mean age (yr) & $61.8(9.6)$ & $64.1(9.3)$ & 0.5 \\
\hline \multicolumn{4}{|l|}{$\begin{array}{l}\text { Location of } \\
\text { tumor }\end{array}$} \\
\hline Splenic flexure & $1(7.1)$ & $3(18.8)$ & 0.6 \\
\hline $\begin{array}{l}\text { Descending } \\
\text { colon }\end{array}$ & $1(7.1)$ & $3(18.8)$ & 0.6 \\
\hline Sigmoid colon & $8(57.1)$ & $7(43.8)$ & 0.72 \\
\hline $\begin{array}{l}\text { Rectosigmoid } \\
\text { colon }\end{array}$ & $4(28.6)$ & $3(18.8)$ & 0.67 \\
\hline \multicolumn{4}{|l|}{ Stage of tumor } \\
\hline Stage II & $4(28.6)$ & $5(31.3)$ & 1 \\
\hline Stage III & $9(64.3)$ & $10(62.5)$ & 1 \\
\hline Stage IV & $1(7.1)$ & $1(6.3)$ & 1 \\
\hline \multicolumn{4}{|l|}{ ASA Group } \\
\hline 1 & $3(21.4)$ & $2(12.5)$ & 0.64 \\
\hline 2 & $8(57.1)$ & $10(62.5)$ & 1 \\
\hline 3 & $3(21.4)$ & $4(25)$ & 1 \\
\hline \multicolumn{4}{|l|}{ Comorbidities } \\
\hline Cardiovascular & $3(21.4)$ & $4(25)$ & 1 \\
\hline $\begin{array}{l}\text { Respiratory } \\
\text { system }\end{array}$ & $2(14.3)$ & $1(6.3)$ & 0.59 \\
\hline Diabetes & $1(7.1)$ & $2(12.5)$ & 1 \\
\hline
\end{tabular}

Table 1: Comparison of clinical characteristics between the stenting and emergency surgery groups. ASA - American Society of Anesthesiologists.

In group A 4 patients out of 14 (not successful stenting procedure) had undergone Hartmann's procedure, in 10 out of 14 pa- tients (successful stenting procedure) had undergone different types of colon resections with primary anastomosis. In group B 12 patients $(75 \%)$ had undergone Hartmann's procedure, rest 4 patients $(25 \%)$ had undergone different types of colon resections with primary anstomosis. There was no mortality in group A, but there was 1 mortality in group B (due to pulmonary embolism). Length of surgeries in stenting group was $145 \pm 27 \mathrm{~min}$ and length of emergency surgeries was - $151 \pm 23 \mathrm{~min}$. In group A, there were 4 complications $(28.6 \%$ ) ( 1 intra abdominal abscess after colorectal anastomosis, which was cured with antibiotic therapy and percutaneous drainage; 3 cases of wound infections) and in Group B there were 8 (50\%) complications (6 with wound infections, 1necrosis of colostomy 1 - leak of colorectal anastomosis). But this difference is not statistically reliable. In group A hospital stay days were - 6 days and in Group B, it was 8 days. This difference is statistically reliable $(\mathrm{P}=0.02)$ (Table 2$)$.

\begin{tabular}{|l|c|c|c|}
\hline \multicolumn{1}{|c|}{ Characteristics } & $\begin{array}{c}\text { Stenting } \\
\text { group } \\
\text { (n= 14) }\end{array}$ & $\begin{array}{c}\text { Emergency } \\
\text { surgery } \\
\text { group } \\
\text { (n= 16) }\end{array}$ & P value \\
\hline Operations & & & \\
\hline $\begin{array}{l}\text { Hartmanns' } \\
\text { procedure }\end{array}$ & $4(28.6)$ & $12(75)$ & 0.03 \\
\hline Left hemicolectomy & $3(21.4)$ & $1(6.25)$ & 0.32 \\
\hline Sigmoid resection & $4(28.6)$ & $3(18.8)$ & 0.67 \\
\hline $\begin{array}{l}\text { High anterior } \\
\text { resection }\end{array}$ & $2(14.3)$ & $0(0)$ & 0.21 \\
\hline Subtotal colectomy & $1(7.1)$ & $0(0)$ & 0.47 \\
\hline Operation time (min) & $145.3(27.5)$ & $151.8(23.4)$ & 0.49 \\
\hline $\begin{array}{l}\text { postoperative } \\
\text { complications }\end{array}$ & $4(28.6)$ & $8(50.0)$ & 0.28 \\
\hline Hospital stay (days) & $6.1(2.1)$ & $8.1(2.2)$ & 0.02 \\
\hline Mortality & 0 & $1(6.25)$ & 1 \\
\hline
\end{tabular}

Table 2: Comparison of surgical outcomes between the stenting and emergency surgery groups.

Data are expressed as mean (SD) or absolute number of patients (\%).

\section{Discussion}

The early signs of bowel obstruction are revealed in 10-30\% of colorectal cancer patients $[8,9]$. Bowel obstruction is mostly complication of left sided colon cancer. Most patients as a rule need to be done emergency operations, with high rate of complications and 
lethal outcome. In case of elective surgery, this complication rate is significantly low [8,10-12]. It should be mentioned also, that these patients will have different type of colostomas whole their remaining life and of course it affects the quality of their life $[8,12,13]$.

From 90s there are used different types of stents for treatment of obstructed bowel, except emergency surgeries [3,4]. Colon stenting will give us chance to perform elective surgeries with primary anastomosis in case of resectable cancers, after decompression [14-16]. There are quite a lot different data in literature about advantages of stenting procedure. Some scientists prove that stents are superior to emergency operations [15,17-19], although there are some scientists, who can't prove stents priority in their trials [20-23].

According to the results of our study, there are more surgical operations with primary anastomosis in stenting group, than in emergency surgery group and the results are statistically relevant $(\mathrm{P}=0.03)$. This fact is considerable because the patients, who had undergone stenting procedure, didn't need forming of colostomy and their quality of life is better, than in case of emergency surgery patients. This result of our study is identical to other studies [14,15,24-26]. Although, there are some studies, where these differences are not manifested $[8,20,22,23]$.

In our study, there is one more statistically reliable difference between these groups: this is hospital stay days. In patients, who have undergone surgical treatment after stenting procedure, hospital stay days are less, than in case of emergency surgery patients $(P=0.02)$. These results of our study are identical to some other studies $[14,15,26]$, but there are also the studies with the different results $[8,21,23]$.

As for the results about postoperative complications, the duration of operation and mortality, there are no significant statistical differences between the groups. There are different data in literature about these parameters. It is considerable, that the number of the scientist, who are unable to detect these differences, is much more bigger $[20-23,25,26]$, rather than the number of the scientist, who note that the rate of complications and mortality is higher in the emergency surgery group $[24,27]$.

The limitations of the study are the non-randomized design, small sample size and unexplored long-term outcomes (recurrence of cancer, survival rate).When reviewing the scientific literature, the following fact was noted: There are quite a few studies where there would be compared long-term oncological outcomes from each group. Therefore, it's needed to conduct large, multicenter, randomized trials which will study both methods and their shortterm and long-term oncological outcomes.

\section{Conclusions}

According to the results of our study, we can make the following conclusions: in case of bowel obstruction by resectable colorectal cancer, colon stenting followed with elective surgery, should be preferred rather than emergency surgery. In future it's needed to perform the randomized trials, which will study the long-term outcomes (recurrence of cancer, survival rate) of this treatment method.

\section{Conflict of Interest Statement}

The authors declare that they have no conflict of interests.

\section{Sources of Funding}

This research did not receive any specific grant from funding agencies in the public, commercial, or non-profit sectors.

\section{Acknowledgments}

Not applicable.

\section{Bibliography}

1. Deans GT., et al. "Malignant obstruction of the left colon". British Journal of Surgery 81 (1994): 1270-1276.

2. Lee YM., et al. "Emergency surgery for obstructing colorectal cancers: a comparison between right-sided and left-sided lesions". Journal of the American College of Surgeons 192 (2001): 719-725.

3. Dohmoto M. "New method-endoscopic implantation of rectal stent in palliative treatment of malignant stenosis". Digestive Endoscopy 3 (1991): 1507-1512.

4. Tejero E., et al. "New procedure for the treatment of colorectal neoplastic obstructions". Diseases of the Colon and Rectum 37 (1994): 1158-1159.

5. Young CJ., et al. "Improving Quality of Life for People with Incurable Large-Bowel Obstruction: Randomized Control Trial of Colonic Stent Insertion". Diseases of the Colon and Rectum 58 (2015): 838-849. 
6. Xinopoulos D., et al. "Stenting or stoma creation for patients with inoperable malignant colonic obstructions? Results of a study and cost-effectiveness analysis". Surgery Endoscopy 18 (2004): 421-426.

7. Suen MK., et al. "How to decide to undertake a randomized, controlled trial of stent or surgery in colorectal obstruction". Surgery 157 (2015): 1137-1141.

8. Frago R., et al. "Current management of acute malignant large bowel obstruction: a systematic review". American Journal of Surgery 207 (2014): 127-138.

9. van de Velde CJ., et al. "Experts reviews of the multidisciplinary consensus conference colon and rectal cancer 2012: science, opinions and experience from the experts of surgery". European Journal of Surgical Oncology (EJSO) 40 (2014): 454-468.

10. Brenner H., et al. "Coloreectal cancer". Lancet 383 (2014): 1490-1502.

11. Smith AJ., et al. "Guideline for optimization of colorectal cancer surgery and pathology". Journal of Surgical Oncology 101 (2010): 5-12.

12. Gainant A. "Emergency management of acute colonic cancer obstruction". Journal of Vascular Surgery 149 (2012): e3-10.

13. Schwenter F., et al. "Management of obstructive and perforated colorectal cancer". Expert Review of Anticancer Therapy 10 (2010): 1613-1619.

14. Hong SP and Kim TI. "Colorectal stenting: an advanced approach to malignant colorectal obstruction". World Journal of Gastroenterology 20 (2014): 16020-16028.

15. Kaplan J., et al. "Enteral stents for the management of malignant colorectal obstruction". World Journal of Gastroenterology 20 (2014): 13239-13245.

16. Kim EJ and Kim YJ. "Stents for colorectal obstruction: Past, present and future". World Journal of Gastroenterology 20 (2014): 842-852.

17. Chouhan H., et al. "Colorectal stenting for malignant obstruction: an 8-year clinical experience". ANZ Journal of Surgery 82 (2012): 408-411.
18. DeCeglie A., et al. "A meta-analysis of endoscopic stenting as bridge to surgery versus emergency surgery for left-sided colorectal obstruction". Critical Reviews in Oncology/Hematology 88 (2013): 387-403.

19. Cirocchi R., et al. "Safety and efficacy of endoscopic colonic stenting as a bridge to surgery in the management of intestinal obstruction due to left colon and rectal cancer: a systematic review and meta-analysis". Surgery on Oncology 22 (2012): 1421.

20. Kavanagh DO., et al. "A comparative study of short-and medium-term outcomes comparing emergent surgery and stenting as a bridge to surgery in patients with acute malignant colonic obstruction". Diseases of the Colon and Rectum 56 (2013): 433440.

21. Sabbagh C., et al. "Is stenting as "a bridge to surgery" an oncologically safe strategy for the management of acute, left-sided, malignant, colonic obstruction? A comparative study with a propensity score analysis". Annals of Surgery 258 (2013): 107115.

22. Ye GY., et al. "Colonic stenting vs emergent surgery for acute left-sided malignant colonic obstruction: a systematic review and meta-analysis". World Journal of Gastroenterology 18 (2012): 5608-5615.

23. Sagar J. "Colorectal stents for the management of malignant colonic obstructions". Cochrane Database System Review (2011): CD007378.

24. Ferrada P., et al. "Surgery or stenting for colonic obstruction: A practice guideline from Eastern Association for the Surgery of Trauma". The Journal of Trauma and Acute Care Surgery 80.4 (2016): 659-664.

25. De Simone B., et al. "Preoperative colonic stents vs emergency surgery for acute left-sided malignant colonic obstruction: meta-analysis with systematic review of the literature". World Journal of Meta-Analysis 5.1 (2017): 1-13.

26. Jain SR., et al. "Compaarison of colonic stents, stomas and resection for obstructive left colon cancer: a meta-analysis". Techniques in Coloproctology (2020). 
27. Allievi N., et al. "Endoscopic stenting as bridge to surgery versus emergency resection for left-sided malignant colorectal obstruction: An updated meta-analysis". International Journal of Surgical Oncology (2017): 2863272.

\section{Assets from publication with us}

- Prompt Acknowledgement after receiving the article

- Thorough Double blinded peer review

- Rapid Publication

- Issue of Publication Certificate

- High visibility of your Published work

Website: www.actascientific.com/

Submit Article: www.actascientific.com/submission.php

Email us: editor@actascientific.com

Contact us: +919182824667 